\title{
Intellectual abilities among survivors of childhood leukaemia as a function of CNS irradiation
}

\author{
CHRISTINE EISER \\ From the Department of Psychological Medicine, The Hospital for Sick Children, London
}

SUMMARY Twenty-eight children in remission at least 2 years after completing chemotherapy for acute lymphoblastic leukaemia were assessed on standardised psychological tests. It was found that 7 who never had central nervous system (CNS) irradiation and 9 having prophylactic CNS irradiation at least 6 months after diagnosis tended to perform at average or above levels, while those 10 each having prophylactic CNS irradiation (within 2 months of diagnosis) were generally of lower ability. Within the latter group, 3 children showed serious intellectual impairments, while the group as a whole functioned especially poorly on quantitative tasks and those involving speeded performance with abstract material. General language ability was not affected. Practical and theoretical implications are discussed.

Research on the effects of brain insults early in life has led to two opposing views regarding subsequent recovery. It has frequently been argued that injury to the central nervous system (CNS) in the young is less severe than the effects of comparable injury in the adult, and that the developing organism is therefore endowed with compensatory mechanisms which the adult lacks. In line with this view, studies of brain injury (Lenneberg, 1967) have claimed that apparently similar degrees of injury have a less deleterious effect on the young than on the adult, and this applies especially to the recovery of language functions. The alternative to this hypothesis of sparing of the younger brain is the view that the less developed brain is, in fact, more vulnerable to adverse influences than the mature brain (Dobbing, 1968). Thus, although extreme malnutrition does not appear to cause intellectual deterioration in the adult, the effects on the young are severe and often irreversible (e.g. Hoorweg and Stanfield, 1976). With recent advances in the treatment of childhood leukaemia, especially acute lymphoblastic leukaemia (ALL), a new group of children is emerging who have survived early brain insults, notably in the form of CNS irradiation and long-term chemotherapy. The purpose of this paper is to report on the intellectual development of this group of children.

There have been several reports that the survivors of ALL and its treatment show abnormal psychological and psychiatric functioning. Meadows and Evans (1976), for example, studying 23 children at

Received 13 October 1977 least 5 years after diagnosis, reported that only 9 showed no abnormal psychiatric functioning, and that the incidence of pathology was greater among those treated by CNS irradiation than those not undergoing this treatment. Only one of 5 children assessed psychologically was reported to show 'normal' intellectual ability. Eiser and Lansdown (1977) studied 15 children, all of whom had undergone a course of CNS irradiation followed by at least 2 years of chemotherapy. When assessed, they were no longer undergoing treatment but remained in remission. The performance of each child on standardised psychological tests was compared with that of one other child, matched in terms of age, sex, and social class, but with no history of serious illness. For children beginning treatment after 5 years of age, there were no differences on any tests between those treated for ALL and their matched controls. Children beginning treatment before this age, however, tended to function at levels below their controls. The difference in favour of the healthy children was particularly noticeable in measures of quantitative, memory, and motor skills, but not in measures of verbal ability or reading.

An apparent contradiction to these findings is found in a study by Soni et al. (1975) who reported that children treated for ALL by CNS irradiation did not function at lower intellectual levels than either (1) children treated for solid tumours by irradiation to parts of the body other than the CNS, or (2) children treated for ALL but not by CNS irradiation. However, there are three main problems associated with these findings. First the number of 
children assessed was very small (only 5 children in one group). Second, Soni et al. did not control for age when comparing children treated for ALL and for solid tumours (mean age of former group, 5 years; of latter group, 10 years). Third, it was noted that on repeated testings children with solid tumours actually improved their scores, while those treated for ALL simply maintained base rates of functioning. A possible inference from this finding may be that CNS irradiation impairs performance over time by blunting the child's ability to benefit from previous learning experiences.

Indications of impairment such as these raise at least two questions for future research. Of major interest is the possible cause of impairment. Although CNS irradiation might be the crucial factor, other researchers have argued that chemotherapy, or an interaction between chemotherapy and CNS irradiation, may be as important (Price and Jamieson, 1975). Reduced school attendance may also be involved, although this was not found to be so by Eiser and Lansdown (1977). The child's intellectual growth may also be affected by psychological stress associated with unpleasant medical procedures, or by parents' and teachers' attitudes to the disease (e.g. McCarthy, 1975). Finally, there may well be a deteriorating process associated with the disease itself. Under current treatment regimens it is not possible to isolate any of these causes. However, given previous findings regarding the effects of irradiation on intellectual ability (e.g. Wood et al., 1967), this study attempts to assess children treated for ALL but differing primarily with regard to whether, and when, they received CNS irradiation.

A second question relates to the degree and type of impairment experienced by the child. Previous research has not been directed at the issue of whether the overall impairment noted is the result of a small generalised deterioration among all children (as would be predicted by the hypothesis of vulnerability), or whether a proportion of children show more serious deficits. In addition, it is not established that children treated for ALL show deterioration in all modes of intellectual functioning, or if some abilities are more at risk than others. Typically, in cases of brain injury, language ability is not affected, while measures involving problem solving in novel situations (Reed and Reitan, 1963), or tests involving heterogeneous skills (such as in the coding subtest or the WISC; Reitan, 1966) are particularly sensitive.

\section{Method}

Twenty-eight children took part in the study; all being patients at the Hospital for Sick Children, the Royal Marsden Hospital, Sutton, Surrey, or the Royal Hospital for Sick Children, Bristol. The criterion for inclusion was that all children should have remained in remission for at least 2 years after completion of chemotherapy. For the purpose of the study children were divided into three groups according to when they had undergone CNS irradiation. One group of children had never had this form of treatment. A second group of 9 children had had prophylactic CNS irradiation at least 6 months after diagnosis; and a third group of 10 children had the more standard treatment of prophylactic CNS irradiation within 2 months of diagnosis. Details of the three groups are given in Table 1.

In addition, the scores of 2 children will be considered separately. One child (A) had undergone CNS irradiation after a known CNS relapse, and a second child (B), although undergoing CNS irradiation early after diagnosis, had received a reduced dose (1000 rads) to the cranium. All other children undergoing CNS irradiation had received dosages in the region of 2400 rads to the cranium, while some had also had lower levels of irradiation to the spine.

All children were assessed individually using (1) the revised Wechsler Intelligence Scale for Children and (2), the Burt reading test.

\section{Results}

Children's scores on all tests were converted to the standardised forms, and mean standardised scores for each of the three groups were compared using Duncan's multiple ranges test (Table 2). Nonsignificant differences between any two groups are

Table 1 Details of the three groups studied

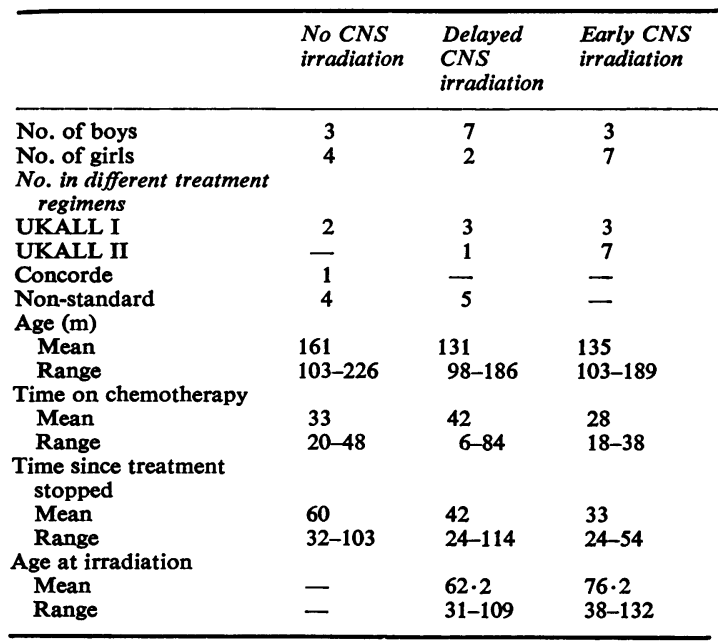


Table 2 Mean scores for the three groups, no CNS irradiation, delayed, and early CNS irradiation

\begin{tabular}{lccc}
\hline & $\begin{array}{l}\text { No } \\
\text { irradiation }\end{array}$ & $\begin{array}{l}\text { Delayed } \\
\text { irradiation }\end{array}$ & $\begin{array}{l}\text { Early } \\
\text { irradiation }\end{array}$ \\
\hline Full scale IQ & $102.4 \mathrm{a}$ & $108.8 \mathrm{a}$ & $88.6 \mathrm{~b}$ \\
Verbal scale IQ & $98.0 \mathrm{a}$ & $108.2 \mathrm{~b}$ & $92.0 \mathrm{a}$ \\
Information & $8.14 \mathrm{a}$ & $9.56 \mathrm{a}$ & $7.70 \mathrm{a}$ \\
Similarities & $11.29 \mathrm{a}$ & $12.78 \mathrm{a}$ & $8.70 \mathrm{~b}$ \\
Arithmetic & $9.43 \mathrm{a}, \mathrm{b}$ & $10.89 \mathrm{a}$ & $7.70 \mathrm{~b}$ \\
Vocabulary & $9.86 \mathrm{a}$ & $12.56 \mathrm{~b}$ & $10.20 \mathrm{a}$ \\
Digit span & $10.29 \mathrm{a}$ & $10.56 \mathrm{~b}$ & $9.40 \mathrm{a}$ \\
Performance scale IQ & $107.3 \mathrm{a}$ & $108.0 \mathrm{a}$ & $87.7 \mathrm{~b}$ \\
Picture completion & $11.71 \mathrm{a}$ & $11.78 \mathrm{a}$ & $9.00 \mathrm{~b}$ \\
Block design & $11.57 \mathrm{a}$ & $11.78 \mathrm{a}$ & $8.80 \mathrm{~b}$ \\
Object assembly & $10.43 \mathrm{a}$ & $9.78 \mathrm{a}$ & $7.00 \mathrm{~b}$ \\
Coding & $10.57 \mathrm{a}$ & $10.56 \mathrm{a}$ & $7.60 \mathrm{~b}$ \\
\hline
\end{tabular}

Nonsignificant differences between two groups are indicated by same subscripts; significant differences $(P<0.05)$ by means of different subscripts.

indicated by use of the same subscripts, while any significant $(P<0.05)$ differences in scores between two groups are indicated by different subscripts.

In general, differences between the groups having no CNS irradiation and delayed CNS irradiation are negligible, while both groups tend to perform consistently above the group undergoing early CNS irradiation. This difference applies to overall IQ score. It does not apply to verbal IQ alone, nor to some of the components of this scale, including measures of general information, vocabulary, and short-term memory (digit span). However, the group having early CNS irradiation scored lower than the other groups on the similarities subtest (involving verbal reasoning rather than overlearned language skills) and arithmetic. A similar pattern showing relatively superior abilities among those having no or later CNS irradiation was found on the performance scale IQ, and on all subtests of this scale. Thus, children undergoing early CNS irradiation score as well as children in the other groups only on measures of language ability. They score below these two groups in both quantitative and verbal reasoning tests, and in all measures of the performance scale which involve novel and abstract material, usually where speed is also critical.

Reading ages of all but 2 children were appropriate for their chronological ages. The two exceptions were in the group having early CNS irradiation, both children scoring 2 years below expected levels.

In order to assess whether the observed poor performance of children in the early irradiation group reflected slightly lower scores for all or if a few children functioned at very much lower levels, the individual scores for verbal and performance scale IQ are given in Table 3.

The verbal scale IQ is comparable for all three groups, and this also applied to the subtests of this scale, as shown in the example of the vocabulary subtest. For performance scale IQ, however, it was apparent that children in the no irradiation or delayed irradiation groups were in the average to above-average range. Individual scores for children in the early irradiation group are generally lower. No child scored in the above average range $(>110)$ and only half scored within an average range (90-110). This pattern was reflected in all subtests of the scale, as shown by the scores on the coding subtest. Both findings might be tentatively interpreted as support for the idea of generalised deficit among all children. In addition, 3 of the 10 children obtained performance scale scores $(<80)$ indicative of more severe deficits in intellectual potential.

As shown in Table 4, a series of correlations were conducted between factors such as the age the child had CNS irradiation, length of time undergoing chemotherapy etc., with scores on all tests. These correlations were conducted separately for each of the three groups. There was only one set of statistically significant findings; among children undergoing delayed CNS irradiation, those having irradiation at a younger age tended to have lower scores than those undergoing the same treatment at a later age. Although such a correlation was not found for

Table 3 Individual scores on verbal scale IQ (VSIQ) with vocabulary subtest and performance scale IQ (PSIQ) with coding subtest

\begin{tabular}{|c|c|c|c|c|c|c|c|c|c|c|c|}
\hline \multicolumn{4}{|c|}{ No CNS irradiation } & \multicolumn{4}{|c|}{ Delayed CNS irradiation } & \multicolumn{4}{|c|}{ Eearly CNS irradiation } \\
\hline VSIQ & $V o c a b$ & $P S I Q$ & Coding & VSIQ & $V o c a b$ & PSIQ & Coding & VSIQ & $V o c a b$ & PSIQ & Coding \\
\hline $\begin{array}{r}98 \\
91 \\
112 \\
95 \\
97 \\
87 \\
106\end{array}$ & $\begin{array}{r}11 \\
10 \\
12 \\
10 \\
9 \\
8 \\
9\end{array}$ & $\begin{array}{l}118 \\
111 \\
111 \\
106 \\
104 \\
101 \\
100\end{array}$ & $\begin{array}{r}12 \\
11 \\
12 \\
9 \\
10 \\
10 \\
10\end{array}$ & $\begin{array}{r}119 \\
119 \\
106 \\
122 \\
108 \\
96 \\
106 \\
106 \\
91 \\
112 \text { (A) }\end{array}$ & $\begin{array}{r}13 \\
15 \\
13 \\
15 \\
11 \\
9 \\
15 \\
13 \\
9 \\
13\end{array}$ & $\begin{array}{r}126 \\
123 \\
115 \\
112 \\
108 \\
100 \\
100 \\
96 \\
92 \\
92\end{array}$ & $\begin{array}{r}14 \\
16 \\
10 \\
10 \\
7 \\
8 \\
12 \\
11 \\
7 \\
8\end{array}$ & $\begin{array}{r}97 \text { (B) } \\
94 \\
105 \\
97 \\
79 \\
95 \\
82 \\
97 \\
81 \\
106 \\
84\end{array}$ & \begin{tabular}{|r|}
8 \\
13 \\
11 \\
12 \\
8 \\
11 \\
8 \\
11 \\
7 \\
14 \\
7
\end{tabular} & $\begin{array}{r}108 \\
108 \\
106 \\
104 \\
100 \\
92 \\
86 \\
85 \\
74 \\
68 \\
54\end{array}$ & $\begin{array}{r}11 \\
10 \\
10 \\
10 \\
8 \\
6 \\
8 \\
7 \\
7 \\
7 \\
3\end{array}$ \\
\hline
\end{tabular}


Table 4 Correlations between age at irradiation and time since irradiation with scores for children having delayed CNS irradiation $(n=10)$

\begin{tabular}{|c|c|c|c|c|}
\hline & \multicolumn{2}{|c|}{ Age at irradiation } & \multicolumn{2}{|c|}{ Time since irradiation } \\
\hline & $r$ & $P$ & $r$ & $P$ \\
\hline $\begin{array}{l}\text { Full scale IQ } \\
\text { Verbal scale IQ } \\
\text { Arithmetic } \\
\text { Digit span } \\
\text { Performance scale IQ } \\
\text { Block design }\end{array}$ & $\begin{array}{l}0.81 \\
0.63 \\
0.74 \\
0.77 \\
0.87 \\
0.79\end{array}$ & $\begin{array}{l}0.009 \\
\text { NS } \\
0.022 \\
0.016 \\
0.002 \\
0.012\end{array}$ & $\begin{array}{l}-0.39 \\
-0.36 \\
-0.57 \\
-0.05 \\
-0.37 \\
-0.49\end{array}$ & $\begin{array}{l}\text { NS } \\
\text { " } \\
\text { " } \\
\text { ", }\end{array}$ \\
\hline
\end{tabular}

children undergoing early CNS irradiation, there appears to be partial support for the earlier finding that younger children may be particularly at risk. There was no significant correlation between test scores and time since irradiation, suggesting that if irradiation is critical, its effects are not reversible over time.

Finally, the scores of the 2 children who were considered separately are shown in the tables where appropriate. The scores for the child having CNS irradiation following a CNS relapse (A) are lower than others undergoing delayed irradiation, but remain within a normal range. Further, this child still scored higher than half of the children undergoing early CNS irradiation. His reading age was, however, 2 years below his chronological age. The child undergoing early CNS irradiation but at a reduced level (B), scored higher than other children undergoing early CNS irradiation.

\section{Discussion}

These data suggest that the use of CNS irradiation does affect a child's subsequent intellectual ability. While the scores achieved by children in the nonirradiated groups are in the average to aboveaverage range, children in the early irradiation group scored in the very low average to average range. Although it is not possible to conclude that early CNS irradiation causes this lowering of performance, it is clear that these children constitute a group of lower intellectual potential.

It was previously reported that children treated for ALL at younger ages function at reduced rates compared with children beginning treatment after 5 years (Eiser and Lansdown, 1977). Again it was found that children treated when younger scored lower than those treated when older for the group undergoing delayed CNS irradiation. The lack of positive correlations between children's scores and time elapsed since irradiation supports the notion that age of irradiation may be the critical factor. While the relationship between test scores and age of irradiation did not appear to be correlated among those undergoing early CNS irradiation, it is possible that the effect was masked due to the fact that 2 of the 3 children showing marked deficits had not begun treatment until 10 years of age. This finding is not reconcilable with the theory of sparing of the younger brain (Smith, 1974), but could be predicted from a hypothesis of vulnerability (Dobbing, 1968). Much evidence is accumulating to suggest that sparing of the younger brain is probably less common than originally thought (Stein et al., 1973), and it is important to distinguish between recovery of functions and damage caused to functions before the actual development.

The scores of the 2 children undergoing slightly modified therapies are particularly useful in conjunction with the group data. In the one case where a child was known to have experienced a CNS relapse, it is clear that his scores remained within average levels, and surprisingly, above levels achieved by some children in the early irradiated group. The second child who underwent early irradiation but at a reduced rate scored higher than other children in the early irradiation group. It is clear that the psychological effects of irradiation must be assessed in relation to the treatment received by the individual and variations from general practice such as these should be monitored especially carefully.

In studies of this kind where multiple factors may be involved in the causation of intellectual deterioration, it may be possible to derive some preliminary indications of the relative importance of different factors by examining the child's performance on different tasks, rather than operating with general IQ scores. In this respect it is suggested that there is less evidence that general psychological stress associated with medical treatment is involved than that actual damage occurs due to CNS irradiation and/or chemotherapy. Measures of both stress and lack of school attendance could be expected to be associated with deteriorating performance on all tests, while it is not clear that they should affect specific tests while leaving language and reading ability unaffected. Further, it is precisely those tests (performance scale items, especially coding) that have previously been associated with brain damage in childhood (Reitan, 1974), which are affected 
among these children. It is especially important to note those areas in which children treated for ALL might show special difficulties. Practically, the teacher may expect verbal achievements to be unaffected, while extra help in the area of quantitative skills may be a reasonable addition to the regular school curriculum.

As all children assessed were attending normal schools and following relatively normal lives, it may be tempting to discuss such deficits as trivial. It is clear on closer inspection, however, that not all children are coping with their environment as easily as might be assumed, and this is particularly disturbing because from a medical point of view they represent an extremely 'successful' group. If such problems exist at least 2 years after completion of treatment, it may well imply that children still undergoing treatment experience similar or even more serious problems.

As with other research on clinical populations, there has been a tendency to regard all children treated for ALL as a homogeneous group, regardless of differences between patients in other experiences or precise differences in medical treatment geared to individual needs (Kinsbourne, 1974; Searleman, 1977). Having established that there is some cause to be concerned for the intellectual abilities of survivors of childhood leukaemia, it is clear that in the future closer attention to such variables is called for. Only by monitoring the psychological development of the individual as a function of his treatment protocol can we hope to establish the precise mechanisms of impairment among these children.

The author is very grateful to Professor R. M. Hardisty and Dr J. M. Chessells of the Hospital for Sick Children, to Dr D. Lawson of the Royal Marsden Hospital, Surrey, and to Professor N. Butler and Dr M. G. Mott of the Royal Hospital for Sick Children, Bristol for help throughout this research; also Professor P. G. Graham, Dr R. Lansdown, and Mrs M. Lobascher for constructive advice at all stages of the project, and Miss $P$. Sorene for typing the manuscript.

\section{References}

Dobbing, J. (1968). Vulnerable periods in developing brain. Applied Neurochemistry, pp. 287-316. Ed. by A. N. Davison and J. Dobbing. Blackwell, Oxford.

Eiser, C., and Lansdown, R. (1977). Retrospective study of intellectual development in children treated for acute lymphoblastic leukaemia. Archives of Disease in Childhood, 52, 525-529.

Hoorweg, J., and Stanfield, J. P. (1976). The effects of protein energy malnutrition in early childhood on intellectual and motor abilities in late childhood and adolescence. Developmental Medicine and Child Neurology, 18, 330-350.

Kinsbourne, M. (1974). Mechanisms of hemispheric interaction in man. Hemispheric Disconnection and Cerebral Function. Ed. by M. Kinsbourne and W. L. Smith. Thomas, Springfield, Illinois.

Lenneberg, E. H. (1967). Biological Foundations of Language. Wiley, New York.

McCarthy, M. (1975). Social aspects of treatment in childhood leukaemia. Social Science and Medicine, 9, 263-269.

Meadows, P. T., and Evans, A. E. (1976). Effects of chemotherapy on the central nervous system. A study of parenteral methotrexate in long-term survivors of leukemia and lyphoma in childhood. Cancer, 37, 1079-1085.

Price, R. A., and Jamieson, P. A. (1975). The central nervous system in childhood leukemia. II. Subacute leukoencephalopathy. Cancer, 35, 306-318.

Reed, H. B. C., Jr., and Reitan, R. M. (1963). Intelligence test performances of brain damaged subjects with lateralized motor deficits. Journal of Consulting Psychology, 27, 102-106.

Reitan, R. M. (1974). Methodological problems in clinical neuropsychology. Clinical Neuropsychology: Current Status and Applications, pp. 19-46. Ed. by R. M. Reitan and L. A. Davison. Winston, Washington, D.C.

Searleman, A. (1977). A review of right hemisphere linguistic capabilities. Psychological Bulletin, 84, 503-528.

Smith, A. (1974). Dominant and non-dominant hemisphererectomy. Hemispheric Disconnection and Cerebral Function. Ed. by M. Kinsbourne and W. L. Smith. Thomas, Springfield, lllinois.

Soni, S. S., Marten, G. W., Pitner, S. E., Duenas, D. A., and Powazek, M. (1975). Effects of central nervous system irradiation on neuropsychologic functioning of children with acute lymphoblastic leukemia. New England Journal of Medicine, 293, 113-118.

Stein, D. G., Rosen, J. J., and Butters, N. (1973). (Editors.) Plasticity and Recovery of Function in the C.N.S. Academic Press, New York.

Wood, J. W., Johnson, K. G., and Omori, Y. (1967). In utero exposure to the Hiroshima atomic bomb-an evaluation of head size and mental retardation: twenty years later. Pediatrics, 39, 385-392.

Correspondence to Dr C. Eiser, Department of Psychological Medicine, The Hospital for Sick Children, Great Ormond Street, London WC1N 3JH. 